\title{
Uterine eosinophils and reproductive performance in interleukin 5-deficient mice
}

\author{
S. A. Robertson ${ }^{1}$, V. J. Mau ${ }^{1}$, I. G. Young ${ }^{2}$ and K. I. Matthaei ${ }^{2}$ \\ ${ }^{1}$ Department of Obstetrics and Gynaecology and Reproductive Medicine Unit, University of Adelaide, Adelaide, SA 5005, Australia; and \\ ${ }^{2}$ Division of Biochemistry and Molecular Biology, John Curtin School of Medical Research, Australian National University, Canberra, \\ ACT 0200, Australia
}

\begin{abstract}
Interleukin 5 is expressed in type $2 \mathrm{~T}$ lymphocytes and has a key role in driving the differentiation, recruitment and activation of eosinophils. Mice with a null mutation in the interleukin 5 gene (IL-5-/- mice) have altered type 2 immune responses and severely depleted eosinophil populations. In the present study, the effect of interleukin 5 deficiency on the abundant population of eosinophils present in the female reproductive tract was investigated, and the reproductive performance in C57Bl/ 6 IL-5 -/- mice was measured. Endometrial eosinophils, detected on the basis of their endogenous peroxidase activity, were reduced in number by four-sevenfold during the oestrous cycle and in early pregnancy in IL-5 -/- mice. Eosinophils present in the cervix and decidual tissues at the time of parturition were similarly diminished. The temporal fluctuations in eosinophil recruitment and localization within these tissues were otherwise unchanged, indicating that interleukin 5 is not a necessary chemotactic agent in the female reproductive tract. Oestrous cycles were moderately greater in duration in IL-5 - / - mice (mean $\pm \mathrm{SD}=5.6 \pm 1.0$ days in IL-5 -/ - mice versus $5.0 \pm 0.8$ days in IL-5 $+/+$ mice $)$, owing to an extended period in oestrus ( $2.7 \pm 0.9$ days per cycle in IL-5 - / mice versus $1.8 \pm 0.7$ in IL- $5+/+$ mice). The interval between placing females with males and the finding of copulatory plugs was reduced significantly in interleukin 5-deficient mice. Implantation rates and subsequent fetal development were comparable in IL-5 -/- and IL-5 +/+ mice, irrespective of whether pregnancies were sired by syngeneic $(\mathrm{C} 57 \mathrm{Bl} / 6)$ or allogeneic $(\mathrm{CBA}$ or $\mathrm{Balb} / \mathrm{c})$ males, apart from a $10 \%$ increase in placental size and a $6.5 \%$ decrease in placental:fetal ratio seen on day 17 in pregnancies sired by CBA males. Parturition and post-partum uterine repair were not compromised in interleukin 5-deficient mice, as judged by the length of gestation, and the outcomes of pregnancies initiated at post-partum oestrus. The birth weights and growth trajectories of pups were significantly influenced by interleukin 5 status, with small but significant increases in the weights of IL-5 -/- pups, particularly $\mathrm{C} 57 \mathrm{Bl} / 6$ and $\mathrm{CBA} \mathrm{F}_{1}$ animals, remaining evident until adulthood. These data are consistent with the view that eosinophils have a role in endometrial tissue remodelling associated with the oestrous cycle, but indicate that the events of pregnancy and parturition proceed quite normally in the absence of maternal and fetal interleukin 5 . However, strain-dependent effects of interleukin 5 deficiency on placental growth and function and subsequent weight gain in the newborn indicate that this cytokine may act through the maternal or fetal immune axis to exert subtle influences on reproductive outcome.
\end{abstract}

\section{Introduction}

Interleukin-5 (IL-5) is a homodimeric cytokine originally recognized for its capacity to stimulate the growth of B cells (Kinashi et al., 1986), the secretion of immunoglobulin A (IgA) (Yokota et al., 1987), and the differentiation, recruit-

Received 23 February 2000. ment and activation of eosinophils (Campbell et al., 1988; Sanderson et al., 1988). A high affinity, heterodimeric receptor complex comprised of an IL-5-specific $\alpha$-subunit and a signal-transducing $\beta$-subunit, shared by the granulocytemacrophage colony-stimulating factor (GM-CSF) and IL-3 receptors, mediates the effects of IL-5 at the target cell surface (Miyajima et al., 1993). 
The opportunity for more precise definition of the biological role of this cytokine has now been afforded by the availability of genetically IL-5-deficient mice, generated using homologous recombination in embryonic stem cells (Kopf et al., 1996). IL-5-deficient mice have smaller CD5+ B cell (B-1 cell) populations in early life (Kopf et al., 1996) and IgA production by B-1 cells in mucosal tissues is moderately impaired (Whittle et al., 1997; Bao et al., 1998), but other cytokines compensate for these functions of IL-5. In contrast, the role of IL-5 in regulating the eosinophil lineage is relatively specific (Sanderson, 1992), and the most marked consequence of IL-5 deficiency is observed in the eosinophil compartment. Basal concentrations of eosinophils are diminished two-threefold in the circulation and bone marrow of IL-5-deficient mice, indicating that steady state production of eosinophils is compromised. The blood and tissue eosinophilia characteristically induced by inflammatory stimuli including helminth infection (Takamoto et al., 1997, Ovington et al., 1998) and aeroallergen challenge (Foster et al., 1996) are completely abolished in IL-5-deficient mice.

Within the peripheral tissues, eosinophils are most plentiful in the mucosal tissues of the gastrointestinal, respiratory and urogenital tracts. Through their secretion of an array of cytokines and potent cationic enzymes, these cells are thought to participate both in regulating local immune events and in orchestrating the breakdown and repair of stromal tissues associated with homeostasis and pathological insults or injury (Sanderson, 1992; Kroegel et al., 1994a,b). Eosinophils have also been postulated to play a role in host defence against parasites and support for this concept has been obtained from studies using IL-5-deficient mice (Matthaei et al., 1997; Ovington et al., 1998).

Eosinophils have long been recognized to comprise an abundant population of cells in the uterine endometrium in rodents. In rats, in which uterine eosinophils have been most comprehensively studied, their numbers fluctuate across the cycle, reaching peak values at oestrus (Ross and Klebanoff, 1966). Comparable patterns are seen in mice, in which the abundance and proximity to the epithelial surface of eosinophils increase further after exposure to semen at mating, and then diminish over subsequent days. By the time of implantation and for the duration of pregnancy, eosinophils are relatively sparse in the endometrial and decidual tissues (De et al., 1991; Robertson et al., 1996). The function of eosinophils in the uterus remains undefined; a role in mediating the oestrogen-induced growth and differentiation of somatic cells has been proposed but not experimentally substantiated (Perez et al., 1996). Recruitment of eosinophils into the cervical and decidual tissues at the time of parturition has also been described in rats and humans (Duchesne and Badia 1992; Knudsen et al., 1997), but studies in mice are more equivocal.

Although IL-5 deficiency is not associated with any overt reproductive incapacity (Kopf et al., 1996), the precise effect of the genotype on reproductive performance has not been examined. The purpose of this study was to undertake a detailed investigation of the uterine eosinophil population and pregnancy outcome in IL-5-deficient mice, to determine the physiological importance of IL-5 in reproduction.

\section{Materials and Methods}

\section{Mice and breeding experiments}

Mice homozygous for a disrupted IL-5 gene (IL-5 -/mice) were generated using gene targeting techniques in C57Bl/ 6 embryonic stem cells (Kopf et al., 1996), and were backcrossed from founder mice into the CBA. $N_{7}$ and Balb/c germlines for seven generations. Heterozygous mice were then intercrossed to produce IL-5 -/- and IL-5 +/+ strains. IL-5 -/ - and wild-type control (IL-5 +/+) mice of each strain were obtained from the Gene Targeting Transgenic Mouse Facility of the John Curtin School of Medical Research. Breeding experiments were conducted in a specific pathogen-free (SPF) facility at the University of Adelaide. Mice were provided with food and water ad libitum.

For analysis of oestrous cycles, vaginal smears were prepared at 10:00-12:00 h each day and examined by phasecontrast microscopy. Mice were allocated to one of four stages of the cycle on the basis of the cellular composition: pro-oestrus (> 50\% intact, live epithelial cells), oestrus $(100 \%$ cornified epithelial cells), metoestrus ( 50\% leukocytes and $\sim 50 \%$ cornified epithelial cells) or dioestrus (> 70\% leukocytes plus cornified or intact epithelial cells). For breeding experiments, adult females (8-12 weeks, IL-5 -/ - or IL-5 + / + C57Bl/6) were housed 2:1 with adult stud males (IL-5 -/- or IL-5 +/+; C57Bl/6 for syngeneic matings and CBA or Balb/c for allogeneic matings) and allowed to mate naturally. The day on which a copulation plug was evident was nominated day 1 of pregnancy, and the interval between placing with males and day 1 of pregnancy was noted for each female. In Expt 1, pregnant females were housed separately from males in groups of three to five and killed by cervical dislocation at 10:00-13:00 h on day 17 of pregnancy, when the number of viable and resorbing implantation sites were recorded. Viable fetuses and placentae were dissected free of decidua and fetal membranes and weighed, and the fetal:placental ratio (fetal weight:placental weight) was calculated. In Expt 2, pregnancy was allowed to proceed until term, when the date and time (to the nearest 0.5 day) of parturition, and the number of live pups were recorded. Pups were weighed 14-20 h after birth, and then at 8 days, 3 weeks (weaning) and 6 weeks after birth. In Expt 3, females remained with males for the duration of pregnancy. The time of parturition, and the appearance of a copulation plug within the next $24 \mathrm{~h}$ was recorded. Pups were removed from females mated at postpartum oestrus, and females were housed in groups of three to five until they were killed on day 17 when implantation sites were analysed as described above.

\section{Histochemistry and immunohistochemistry}

Additional groups of IL-5 -/- and IL-5 +/+ female C57Bl/ 6 mice were killed at 10:00-12:00 $\mathrm{h}$ on the days of dioestrus or oestrus, or on day 1 or day 3 of pregnancy after mating with males of the same genotype. The stage of oestrous cycle was evaluated by examination of external vaginal appearance and vaginal smears. Uterine tissue was embedded in OCT compound (Tissue Tek; Bayer Corp., 
Table 1. Effect of interleukin 5 (IL-5) deficiency on eosinophil populations in the mouse endometrial stroma at dioestrus and oestrus, and on day 1 and day 3 of pregnancy

\begin{tabular}{llclc}
\hline & $n$ & IL-5+/+ & $n$ & IL-5-/- \\
\hline Dioestus & 6 & $1.5(0.1-2.9)^{\mathrm{a}}$ & 6 & $0.4(0.0-0.9)^{\mathrm{a}}$ \\
Oestrus & 6 & $11.0(7.9-12.6)^{\mathrm{b}}$ & 6 & $1.9(1.2-3.0)^{\mathrm{b} *}$ \\
Day 1 & 6 & $13.1(12.1-15.8)^{\mathrm{c}}$ & 6 & $1.8(1.2-2.4)^{\mathrm{b} *}$ \\
Day 3 & 6 & $1.5(0.9-1.7)^{\mathrm{a}}$ & 6 & $0.4(0.2-0.8)^{\mathrm{a} *}$ \\
\hline
\end{tabular}

Eosinophils were identified as endogenous peroxidase positive cells in endometrial tissue from C57Bl/6 IL-5 +/ + or IL-5 -/ - mice recovered between 10:00 and 12:00 $\mathrm{h}$ on the day of oestrus or dioestrus, or on day 1 or day 3 of pregnancy after mating with males of the same genotype. The area of staining in sections was determined using Video Pro Image Analysis software. Data are given as median ( $95 \%$ confidence range) per cent positivity. $n$ : number of uteri examined.

Data were compared by Kruskal-Wallis one-way ANOVA followed by Mann-Whitney rank sum test. Different superscripts indicate differences between time points, within genotypes $(P<0.05)$. Asterisks denote significant differences between data from IL-5 -/ - and IL-5 + / + mice $(P<0.005)$.

Elkhart, IN) and frozen in isopropanol cooled by liquid nitrogen. Six micrometre semi-serial sections were cut from an area midway between the cervix and oviductal junction, fixed in $96 \%$ ethanol and immunolabelled. Cervical tissue and decidual tissue from implantation sites or placental scars were recovered from IL-5 -/ - and IL-5 + / + females during parturition (after the birth of at least two pups) or within $6 \mathrm{~h}$ of the completion of delivery.

Eosinophils in endometrium and cervical tissue were detected on the basis of their endogenous peroxidase activity (King et al., 1981) by incubating slides in diaminobenzidine (DAB; Sigma) (5 mg ml-1 in 0.05 mol Tris- $\left.\mathrm{HCl} \mathrm{l}^{-1}, \mathrm{pH} 7.2\right)$ plus $0.02 \%$ hydrogen peroxide for $10 \mathrm{~min}$ at room temperature, or by the Sirius red or Congo red techniques (Bancroft and Stevens, 1990). Endometrial tissue from cyclic and mated mice was also stained with monoclonal antibodies (mAbs, from the American Type Culture Collection, Rockville, MD) rat anti-mouse F4/80 (which is specifically reactive with macrophages; Austyn and Gordon, 1981) and rat anti-mouse CD45 (leukocyte common antigen (LCA), TIB122, which is specifically reactive with all leukocytes). Reactivity was visualized using biotinylated goat anti-rat antibody and streptavidin-horseradish peroxide as described by Robertson et al. (1992). All tissues were counterstained in haematoxylin. The area of positive DAB staining in the endometrial stroma (expressed as a function of the area of total staining) was determined by video image analysis using Video Pro software (Faulding Imaging, Adelaide).

\section{Statistical analyses}

Immunohistochemistry data were analysed by KruskalWallis one-way ANOVA, followed by Mann-Whitney rank sum tests (two-tailed; SPSS Software, Chicago, IL). Fertility data were analysed by ANOVA and Bonferroni $t$ tests (SPSS), with or without inclusion of strain and litter size as covariates, as specified. Data expressed as proportions were analysed by CHITEST and CHIDIST procedures in Excel 5.0 (Microsoft, Redmond, WA). Differences between groups were considered to be significant when $P<0.05$.

\section{Results}

Effect of IL-5 deficiency on uterine eosinophil populations during the oestrous cycle and early pregnancy

Sections of uteri were taken from dioestrous, oestrous, day 1 and day 3 pregnant IL- $5-/-$ and $+/+$ mice $(n=6$ mice per group) to examine the effect of IL-5 deficiency on uterine histology and eosinophil populations in the endometrium. In preliminary experiments using serial sections of uterine tissue, identical staining patterns were found irrespective of whether eosinophils were stained with DAB, Sirius red or Congo red, and DAB was used subsequently for all quantitative analyses. Uteri recovered from oestrous IL-5 -/mice were similar in dimension and wet weight to uteri recovered from cytokine replete mice (data not shown). There were no unusual features or overt differences in the morphology of uteri from IL-5 -/- mice compared with uteri from IL-5 + / + mice, either during the cycle or during early pregnancy. There was no histological evidence of any difference in the thickness of the luminal epithelium, or in the size or number of endometrial glands at any stage.

Previous studies have shown that, during the oestrous cycle, eosinophils are localized predominantly in the stromal tissue at the endometrial-myometrial junction and are most prevalent at oestrus (Ross and Klebanoff, 1966). After mating, eosinophils increase in number and accumulate in the endometrial stroma proximal to the luminal epithelium, then diminish in number by the time of implantation (De et al., 1991; Robertson et al., 1996). These patterns of recruitment and localization in endometrial tissue were evident in the IL$5+/+$ mice studied in the current experiment, with the mean number of endogenous peroxidase-positive cells increasing ninefold from dioestrus to day 1 of pregnancy, then decreasing again by day 3 of pregnancy (Table 1). In IL-5 -/mice, the number of eosinophils in the uterine tissues was reduced markedly, with mean values fourfold lower in tissues from dioestrous and day 3 pregnant mice, and sevenfold lower in tissues from oestrous and day 1 pregnant mice. However, the spatial localization of eosinophils in the uterine tissues and their relative increase in density at 

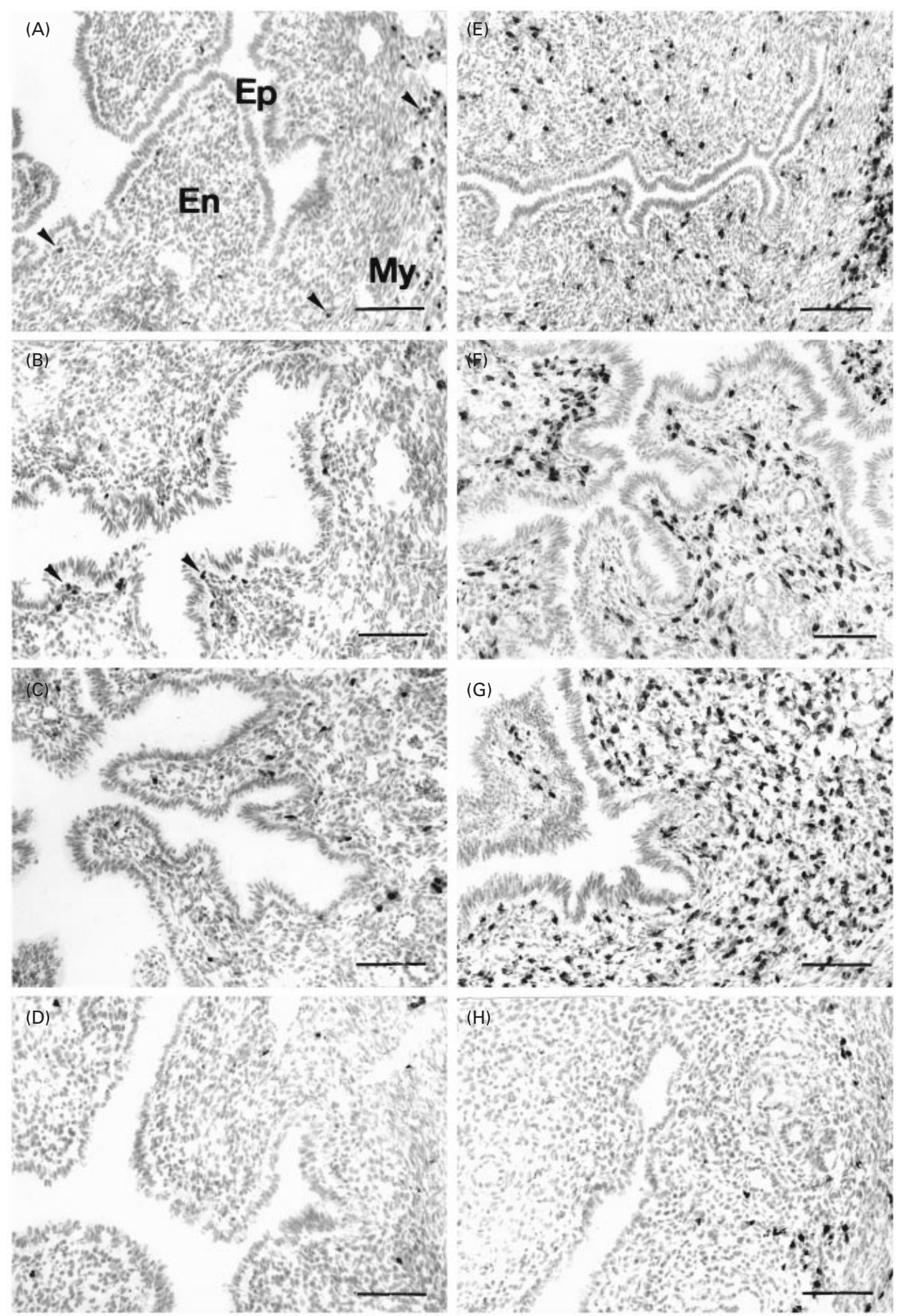

Fig. 1. Histochemical localization of eosinophils (endogenous peroxidase positive cells, arrows) in uteri of interleukin 5 (IL-5) -/ $-(\mathrm{a}-\mathrm{d})$ and IL-5 +/ + (e-h) mice killed at 10:00-12:00 h on the day of dioestrus (a,e), oestrus $(b, f)$, or on day $1(\mathrm{c}, \mathrm{g})$ or day $3(\mathrm{~d}, \mathrm{~h})$ of pregnancy after mating with intact males of the same genotype. Scale bars represent $100 \mu \mathrm{m}$. Ep: epithelium, En: endometrium; My: myometrium. 


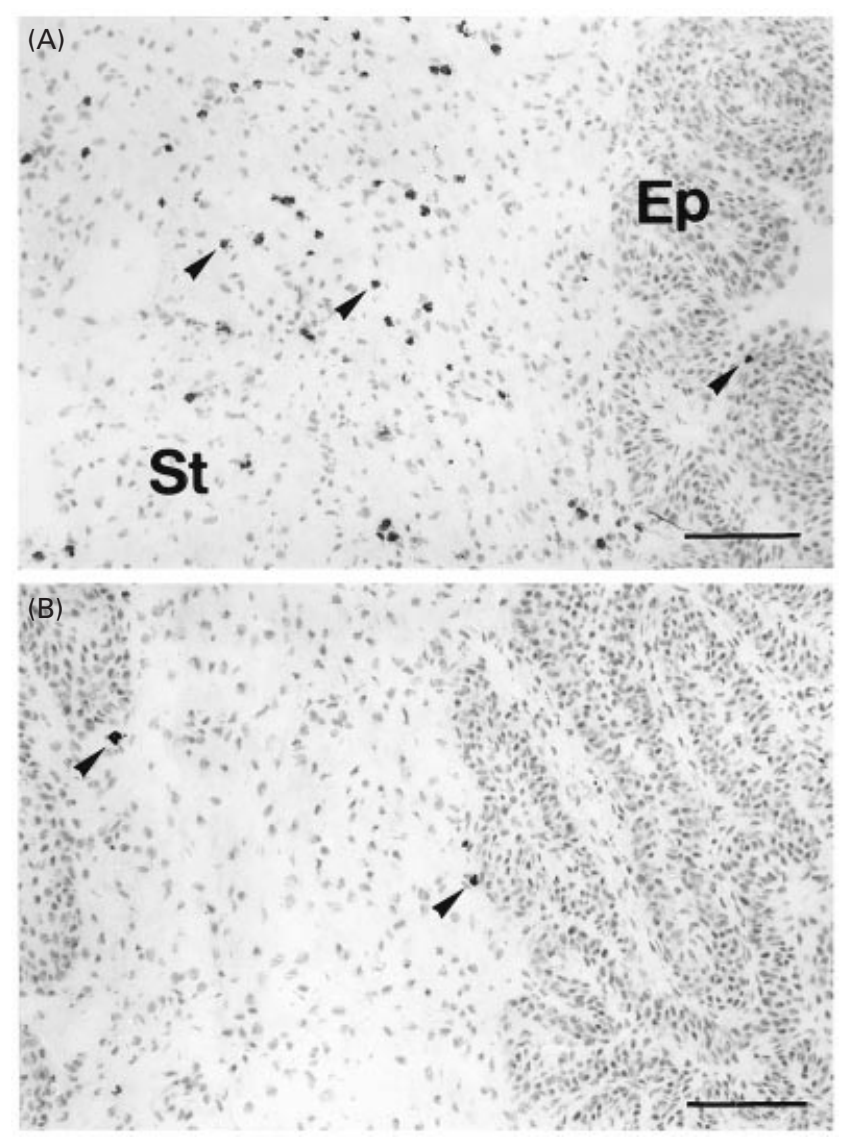

Fig. 2. Histochemical localization of eosinophils (endogenous peroxidase positive cells, arrows) in cervical tissue of interleukin 5 (IL-5) +/+ (a) and IL-5 -/- (b) mice killed during parturition after mating with intact males of the same genotype. Scale bars represent $100 \mu \mathrm{m}$. Ep: epithelium, St: stromal tissue.

oestrus and after mating were comparable in IL-5 -/- and IL$5+/+$ mice (Fig. 1).

Additional tissue sections were labelled immunohistochemically with F4/80 and anti-LCA mAbs to identify macrophages and all leukocytes, respectively, and investigate the potential effect of IL-5 deficiency on other leukocyte populations in the endometrium. There was no effect of IL-5 status on the numbers of macrophages or other leukocyte lineages in the uterine endometrium or myometrium (data not shown). The location of leukocytes within the tissue, including cells previously identified as neutrophils traversing the luminal epithelium in the day 1 pregnant uterus (Robertson et al., 1996), were comparable between the genotypes and similar to those described for other strains of mice (McMaster et al., 1992; Robertson et al., 1996).

\section{Effect of IL-5 deficiency on eosinophils in the cervix and implantation site at parturition}

Primiparous IL-5 -/ - and IL-5 +/ + mice ( $n=4$ mice per genotype) were killed during or immediately after delivery of pups to examine the effect of IL-5 deficiency on eosinophil populations in the implantation site and cervix at the time of parturition. Sections of cervical tissue and decidual tissue from implantation sites and placental scars $(n=3-4$ per mouse) were stained with DAB to identify eosinophils. Eosinophils were distributed in the subepithelial stroma of cervical tissue from IL-5 +/+ mice in densities approximating those seen in dioestrous endometrium, and were considerably diminished in number in IL-5 -/- mice (Fig. 2). Very few eosinophils were identified in decidual tissue either before or after placental separation in IL-5 +/+ mice, and were absent from implantation sites in IL-5 -/ - mice.

\section{Effect of IL-5 deficiency on the oestrous cycle and mating interval}

Daily vaginal smears were taken from virgin IL-5 + / + and IL-5 - / - females ( $n=20$ per group) for 2 weeks to investigate the effect of IL-5 deficiency on the duration of the oestrous cycle. All but one animal in each group demonstrated cyclic behaviour. Cycles were significantly longer in IL-5 -/- mice (mean $\pm \mathrm{SD}=5.6 \pm 1.0$ days versus $5.0 \pm 0.8$ days in IL-5 $+/+$ mice, $P<0.05)$, owing principally to a $50 \%$ increase in the number of days spent in oestrus per cycle (Fig. 3). Indeed, of the total number of vaginal smears examined over the course of the experimental period, 50\% (118/235) from IL-5 -/- mice and 36\% (86/236) from IL-5 +/+ showed a pattern characteristic of oestrus.

A further measure of the effect of IL-5 deficiency on the persistence of oestrus in female mice was made by recording the 'mating interval', defined as the number of days between placing females with stud males and the day of detection of a copulatory plug. IL-5 -/ - and IL-5 +/+ females were mated with $\mathrm{C} 57 \mathrm{Bl} / 6, \mathrm{CBA}$ and Balb/c stud males of the same IL-5 status. Mating interval was significantly affected by the strain of male, with a longer period of housing required to achieve mating with syngeneic $(\mathrm{C} 57 \mathrm{Bl} / 6)$ males than allogeneic (CBA or Balb/c) males (mean \pm SD mating interval $=5.6 \pm 5.0$ and $3.5 \pm 3.0$ days for syngeneic $(n=55)$ and allogeneic $(n=207)$ matings, respectively, $P<0.01)$. After correction for the background strain of stud males, mating interval was found to be significantly lower in IL-5 -/ - mice $(P<0.01)$ (Table 2$)$.

\section{Effect of IL-5 deficiency on litter size, fetal viability, and fetal and placental weights at day 17}

Virgin IL-5 +/+ and IL-5 -/- C57Bl/6 females mated naturally with males of the same genotype were killed on day 17 of pregnancy to determine whether IL-5 status influenced implantation, growth or survival of the conceptus during pregnancy. The proportion of mice plugged on day 1 that were pregnant on day 17 was not affected by genotype (Table 3). The numbers of implantation sites, and the proportions of implantation sites found to be resorbing on day 17 were also comparable. Viable fetuses and placentae were weighted to examine whether parental IL- 5 influences the growth of the placenta or fetus. Fetal and placental 
Table 2. Effect of interleukin 5 (IL-5) status on 'mating interval' in mice

\begin{tabular}{lcccc}
\hline & $n$ & IL-5+/+ & $n$ & IL-5-/- \\
\hline C57Bl/6 stud & 30 & $6.6 \pm 5.7$ & 25 & $4.4 \pm 3.9$ \\
CBA stud & 48 & $4.4 \pm 3.1$ & 53 & $3.9 \pm 3.4$ \\
Balb/c stud & 58 & $3.1 \pm 3.1$ & 48 & $2.8 \pm 1.9$ \\
Total & 136 & $4.3 \pm 0.3$ & 126 & $3.6 \pm 0.3$ \\
\hline
\end{tabular}

Virgin C57Bl/6 IL-5 + / + and IL-5 -/- mice were placed with C57Bl/6, CBA or Balb/c males of the same IL-5 genotype. 'Mating interval' is the number of days between placing females with stud males and the day of detection of a vaginal plug. Data are given as mean \pm SD days. $n$ : number of female mice mated with each type of stud male.

Data were analysed by ANOVA using strain of male as a co-variate. Mating interval was found to be significantly lower in IL-5 -/mice $(P<0.01)$

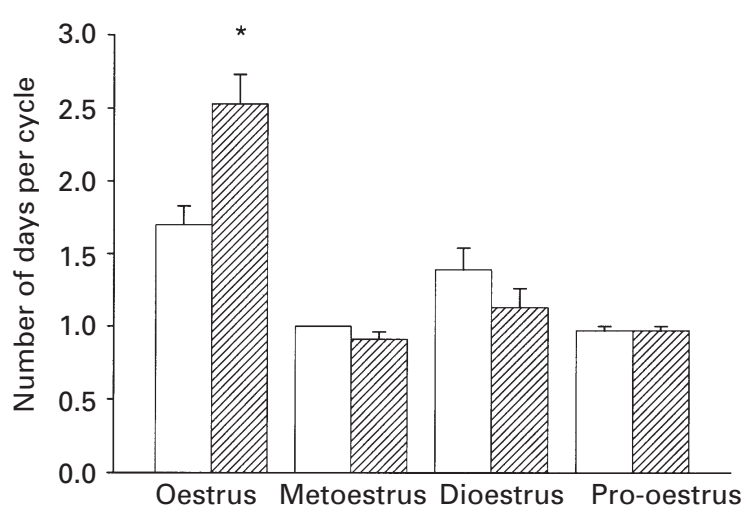

Fig. 3. Effect of interleukin 5 (IL-5) deficiency on the oestrous cycle in mice. The cellular characteristics of daily vaginal smears recorded over 2 weeks in IL-5 +/+ $(\square)$ and IL-5 -/- $(\mathbb{Z})$ mice were assessed microscopically to determine the stage of the oestrous cycle. Data are mean \pm SD number of days spent at each stage of the cycle $(n=20$ per group). Data were analysed by Bonferroni $t$ test. *Significantly different from IL-5 +/+, $P<0.001$.

weight, and the fetal:placental ratio were not influenced by IL-5 deficiency.

IL-5 +/+ and IL-5 -/- C57Bl/6 females were mated naturally with CBA males or Balb/c males of the same IL-5 status and killed on day 17 of pregnancy to investigate whether allogeneic pregnancy is influenced by IL- 5 status. Paternal strain did not affect the number of implantation sites per litter significantly, but fetal resorptions were less common in either allogeneic than in the syngeneic mating combination, irrespective of IL-5 genotype (Table 3; $P<0.01$ ). Fetal weights and fetal:placental ratios were increased in both types of allogeneic pregnancies (Table 3; $P<0.001$ and $P=0.05$, respectively). IL-5 deficiency did not influence the proportion of mated mice maintaining pregnancy to day 17 , the number of implantation sites, or the rate of fetal resorption in either strain combination (Table 3). However, IL-5 deficiency was associated with a significant increase in mean size of placenta in females mated with CBA males $($ mean $\pm \mathrm{SD}=107 \pm 17 \mathrm{mg}$ versus $100 \pm 14 \mathrm{mg}$, respectively; $P<0.005)$ and mean fetal:placental ratio was reduced $(6.3 \pm 1.3$ versus $6.7 \pm 1.2$, respectively, $P<0.005)$. Similar effects were not seen in Balb/c matings, and there was no effect of IL-5 genotype on fetal weight in either group.

\section{Effect of IL-5 deficiency on parturition, perinatal fetal loss} and pup growth trajectories

Virgin IL-5 + / + and IL-5 -/- C57Bl/ 6 females were mated naturally with $\mathrm{C} 57 \mathrm{Bl} / 6, \mathrm{CBA}$ or Balb/c males of the same IL5 genotype and gestation was allowed to proceed to term to determine the effect of IL-5 status on parturition and the neonatal viability and subsequent growth of pups. There was no effect of IL-5 deficiency on the duration of gestation in any strain combination (mean $\pm \mathrm{SD}=19.3 \pm 0.4$ and $19.4 \pm 0.8$ days in IL-5 + / + females $(n=29)$ and IL- $5-/-$ females $(n=$ 37), respectively). Furthermore, the survival of pups during the perinatal and postnatal period was comparable in IL-5deficient and IL-5-replete litters (Table 4).

IL-5 deficiency was associated with small but significant increases in the weight gain trajectories of pups. The extent of the effect was significantly influenced by paternal strain, with allogeneic matings giving rise to larger pups than syngeneic matings $(P<0.001$ at all time points other than at day 8)(Table 5). The greatest differences were evident in CBA $\mathrm{F}_{1}$ pups, in which the mean weights of female and male IL-5 $-/$ - pups at weaning were increased by 9.5 and $10.0 \%$, respectively (both $P<0.01$ ). In $\mathrm{C} 57 \mathrm{Bl} / 6 \mathrm{~F} 1$ pups, the mean weights of female and male IL-5-/- pups at 6 weeks were increased by 7.9 and $12.2 \%$, respectively (both $P<0.01$ ) (Table 5). Analysis of the entire data set using strain as a covariate showed that IL-5 -/- pups were significantly larger than IL-5 +/+ pups from birth until adulthood ( $P<0.001$ at $24 \mathrm{~h}, 8$ days, 3 weeks and 6 weeks after birth).

\section{Effect of IL-5 deficiency on pregnancy outcome after mating at post-partum oestrus}

The capacity of IL-5 -/- females to support pregnancies initiated during postpartum oestrus was examined to investigate the role of IL-5 in postpartum uterine repair. The proportion of females plugged by Balb/c males remaining pregnant at day 17 , and the number of viable fetuses present at day 17 , were both moderately lower in IL-5 - / - than in IL$5+/+$ females, but the differences were not statistically significant (Table 6).

\section{Discussion}

These studies indicate that reproductive performance in mice is largely unaffected by genetic IL-5 deficiency, despite 
Table 3. Effect of interleukin 5 (IL-5) deficiency on fetal and placental parameters at day 17 of syngeneic and allogeneic pregnancies in mice

\begin{tabular}{|c|c|c|c|c|c|c|}
\hline & $\mathrm{C} 57 \mathrm{Bl} / 6+/+$ & $\mathrm{C} 57 \mathrm{Bl} / 6-/-$ & $\mathrm{CBA}+/+$ & $\mathrm{CBA}-/-$ & $\mathrm{Balb} / \mathrm{c}+/+$ & $\mathrm{Balb} / \mathrm{c}-/-$ \\
\hline Number of females plugged & 35 & 37 & 38 & 38 & 35 & 36 \\
\hline $\begin{array}{l}\text { Number of viable pregnancies } \\
\text { at day } 17 \text { ( } \% \text { of plugged) }\end{array}$ & $34(97)$ & $35(95)$ & $32(84)$ & $37(97)$ & $31(89)$ & $32(89)$ \\
\hline $\begin{array}{l}\text { Number of fetuses per litter } \\
\text { Number of viable fetuses per }\end{array}$ & $8.1 \pm 1.7$ & $8.1 \pm 2.0$ & $8.1 \pm 1.7$ & $7.9 \pm 1.7$ & $7.5 \pm 1.9$ & $7.8 \pm 2.3$ \\
\hline litter $(\%$ of total $)$ & $6.9 \pm 1.8(85)$ & $6.9 \pm 2.3(85)$ & $7.6 \pm 2.4(94)$ & $7.5 \pm 2.2(95)$ & $6.8 \pm 2.0(90)$ & $7.4 \pm 2.3(94)$ \\
\hline $\begin{array}{l}\text { Number of resorbing fetuses } \\
\text { per litter }(\% \text { of total })^{\ddagger}\end{array}$ & $1.2 \pm 1.3(15)$ & $1.2 \pm 1.4(15)$ & $0.5 \pm 1.1(6)$ & $0.4 \pm 1.4(5)$ & $0.7 \pm 0.9(10)$ & $0.5 \pm 1.0(6)$ \\
\hline $\begin{array}{l}\text { Number of implants examined } \\
\text { at day } 17\end{array}$ & 208 & 193 & 204 & 240 & 160 & 209 \\
\hline Fetal weight $(\mathrm{g})^{\ddagger}$ & $593 \pm 74$ & $599 \pm 76$ & $670 \pm 90$ & $661 \pm 88$ & $671 \pm 92$ & $670 \pm 101$ \\
\hline Placental weight $(\mathrm{g})^{\dagger \ddagger}$ & $94 \pm 16$ & $97 \pm 15$ & $100 \pm 14$ & $107 \pm 17^{* *}$ & $103 \pm 14$ & $103 \pm 19$ \\
\hline $\begin{array}{l}\text { Fetal weight:placental weight } \\
\text { ratio }{ }^{\ddagger \ddagger}\end{array}$ & $6.4 \pm 1.2$ & $6.3 \pm 1.3$ & $6.7 \pm 1.2$ & $6.3 \pm 1.3^{*}$ & $6.6 \pm 1.2$ & $6.7 \pm 1.5$ \\
\hline
\end{tabular}

Virgin C57Bl / 6 IL-5 + / + and IL-5 -/- mice were mated with C57Bl/6, CBA or Balb/c males of the same IL-5 genotype and killed at day 17 of pregnancy when the numbers of viable and resorbing fetuses, as well as the fetal and placental weight and fetal:placental weight ratio were determined.

Data are given as mean \pm SD.

Data were analysed by one-way ANOVA and Bonferroni $t$ test; * parameter significantly different from CBA $+/+(P<0.05)$; ${ }^{* *}$ parameter significantly different from $\mathrm{CBA}+/+(P<0.01)$.

Data were analysed by univariate ANOVA using strain of male and litter size as co-variates; ${ }^{\dagger}$ parameter significantly influenced by IL-5 genotype $(P<0.005)$;

†parameter significantly influenced by strain of male used in mating $(P<0.01)$.

Table 4. Effect of interleukin 5 (IL-5) status on perinatal viability and pup survival to weaning after syngeneic and allogeneic pregnancy in mice

\begin{tabular}{|c|c|c|c|c|c|c|}
\hline & $n$ & $\mathrm{IL}-5+/+$ & Pups lost (\%) & $n$ & IL-5-/- & Pups lost (\%) \\
\hline \multicolumn{7}{|c|}{ Syngeneic pregnancy (sired by C57Bl / 6 males) } \\
\hline Day 17 of pregnancy & 35 & $6.9 \pm 1.8$ & & 37 & $6.9 \pm 2.3$ & \\
\hline 14-22 h after birth & 9 & $6.0 \pm 2.0$ & $(\sim 13 \%)$ & 9 & $5.9 \pm 2.8$ & $(\sim 14 \%)$ \\
\hline Day 8 after birth & 9 & $5.1 \pm 2.2$ & $8 / 54(15 \%)$ & 9 & $5.1 \pm 2.9$ & $7 / 53(13 \%)$ \\
\hline Weaning & 9 & $5.1 \pm 2.2$ & $0 / 46(0 \%)$ & 9 & $5.1 \pm 2.9$ & $0 / 46(0 \%)$ \\
\hline \multicolumn{7}{|c|}{ Allogeneic pregnancy (sired by CBA or Balb/c males) } \\
\hline Day 17 of pregnancy & 60 & $7.3 \pm 2.2$ & & 69 & $7.4 \pm 2.2$ & \\
\hline $14-22 \mathrm{~h}$ after birth & 25 & $7.3 \pm 2.3$ & $(\sim 0 \%)$ & 29 & $7.3 \pm 2.2$ & $(\sim 1 \%)$ \\
\hline Day 8 after birth & 25 & $7.1 \pm 2.4$ & $6 / 184(3.2 \%)$ & 29 & $7.2 \pm 2.2$ & $3 / 212(1.4 \%)$ \\
\hline Weaning & 25 & $7.1 \pm 2.4$ & $1 / 178(0.6 \%)$ & 29 & $7.2 \pm 2.2$ & $1 / 209(0.5 \%)$ \\
\hline
\end{tabular}

Virgin C57Bl/6 IL-5 + / + and IL-5 -/- mice were mated with C57Bl/6 males (syngeneic pregnancy) or CBA or Balb/c males (allogeneic pregnancy) of the same IL5 genotype. Data are given as mean \pm SD number of viable implantation sites on day 17 of pregnancy (from Expt 1 , Table 3 ) or mean \pm SD number of viable pups at 14-22 h after birth, 8 days after birth and weaning ( 3 weeks after birth) (Expt 2 ). The number (\%) of pups lost at each developmental stage is also given. $n$ : number of litters.

a marked reduction in the number of eosinophils resident in the uterus at the initiation of pregnancy, and in the cervix at parturition. A moderate increase in placental size and decrease in the fetal:placental weight ratio, indicating reduced placental efficiency, was the only consequence of IL5 deficiency detectable during pregnancy, and was limited to one of two mating combinations $(\mathrm{C} 57 \mathrm{Bl} / 6$ females $\times \mathrm{CBA}$ males) in which fetuses were allogeneic relative to the mother. However, IL-5 -/- pups were larger than IL-5 +/+ pups at birth and through the first 6 weeks of life, and this effect was most pronounced in $\mathrm{CBAF}_{1}$ animals.

Eosinophil depletion from the uterine tissues of IL-5deficient mice was comparable in extent with that reported for the blood and bone marrow before parasite infection
(Kopf et al., 1996; Takamoto et al., 1997). Lack of IL-5 did not alter the pattern of infiltration and localization into the subepithelial stroma of the uterus exhibited by the small residual population. This finding is consistent with the notion that IL-5 contributes significantly to generating the pool of eosinophils recruited from the circulation into the uterus, but indicates that cytokines other than IL-5 are responsible for eliciting their extravasation and movement through the uterine stroma. Eotaxin, RANTES and macrophage inflammatory protein (MIP) $1 \alpha$ are eosinophil chemokines implicated in this role, since their synthesis in the endometrium fluctuates in response to ovarian steroid hormones and in parallel with eosinophil infiltration in mice (Robertson et al., 1998) and humans (Zhang et al., 2000). 
Table 5. Effect of fetal and maternal interleukin 5 (IL-5) deficiency on post-natal growth trajectory after syngeneic and allogeneic pregnancy in mice

\begin{tabular}{|c|c|c|c|c|c|c|c|c|c|c|c|c|c|}
\hline & & \multicolumn{4}{|c|}{$\mathrm{C} 57 \mathrm{Bl} / 6$} & \multicolumn{4}{|c|}{ CBA } & \multicolumn{4}{|c|}{ Balb/c } \\
\hline & & $n$ & IL-5 +/+ & $n$ & IL-5 -/- & $n$ & IL-5 +/+ & $n$ & IL-5 -/- & $n$ & IL-5 +/+ & $n$ & IL-5 -/- \\
\hline $\operatorname{Day} 1^{\ddagger}$ & & 52 & $1.29 \pm 0.15$ & 52 & $1.36 \pm 0.15$ & 110 & $1.40 \pm 0.10$ & 118 & $1.45 \pm 0.14$ & 63 & $1.44 \pm 0.18$ & 94 & $1.42 \pm 0.14$ \\
\hline Day 8 & & 46 & $4.10 \pm 0.49$ & 40 & $3.97 \pm 0.32$ & 108 & $4.02 \pm 0.28$ & 117 & $4.24 \pm 0.48^{*}$ & 70 & $3.78 \pm 0.45$ & 92 & $3.88 \pm 0.50$ \\
\hline \multirow[t]{2}{*}{3 weeks } & Female ${ }^{\ddagger}$ & 44 & $8.20 \pm 1.06$ & 39 & $8.10 \pm 1.61$ & 54 & $9.14 \pm 0.79$ & 57 & $10.01 \pm 0.80^{*}{ }^{\dagger}$ & 34 & $9.36 \pm 0.68$ & 53 & $9.17 \pm 0.88$ \\
\hline & Male $^{\ddagger}$ & 43 & $8.66 \pm 1.37$ & 47 & $8.62 \pm 1.53$ & 53 & $9.29 \pm 0.74$ & 60 & $10.24 \pm 0.82^{*}$ & 36 & $9.60 \pm 1.19$ & 37 & $9.22 \pm 0.85$ \\
\hline \multirow[t]{2}{*}{6 weeks } & Female ${ }^{\ddagger}$ & 29 & $16.4 \pm 1.5$ & 33 & $17.7 \pm 0.5^{*}$ & 56 & $18.3 \pm 0.7$ & 57 & $18.5 \pm 0.9$ & 34 & $19.1 \pm 1.2$ & 52 & $18.8 \pm 1.1$ \\
\hline & Male $\ddagger$ & 33 & $19.7 \pm 1.8$ & 34 & $22.1 \pm 2.0^{*}$ & 52 & $22.3 \pm 2.4$ & 59 & $22.9 \pm 1.4$ & 37 & $23.2 \pm 1.2$ & 39 & $23.8 \pm 1.3$ \\
\hline
\end{tabular}

Pups are the progeny of virgin C57Bl/6 IL-5 + / and IL-5 -/- mice mated with C57Bl/6 males (syngeneic pregnancy) or CBA or Balb/c males (allogeneic pregnancy) of the same IL-5 genotype.

Data are mean \pm SD weights of viable pups measured on day 1 (14-20 h after birth), and at 8 days, 3 weeks and 6 weeks of age. $n$ : number of pups.

Data catagorized by group were analysed using one-way ANOVA followed by Bonferroni $t$ test. *Significantly different from IL-5 + $+(P<0.01)$, when each pup comprises an individual observation. ${ }^{+}$Significantly different from IL- $5+/+(P<0.05)$, when each litter comprises an individual observation.

Data catagorized by allogenic or syngeneic pregnancy were analysed by Bonferroni $t$ test. $\ddagger$ Parameter significantly influenced by genetic disparity between parents $(P<0.001)$, both when each pup comprises an individual observation, and when each litter comprises an individual observation.

Table 6. Effect of interleukin 5 (IL-5) deficiency on fetal and placental parameters at day 17 of allogeneic pregnancy following postpartum mating in mice

\begin{tabular}{llc}
\hline & Balb/c $+/+$ & Balb/c-/- \\
\hline Number of females plugged & 14 & 21 \\
Number of viable pregnancies at day 17 (\% of plugged) & $13(93)$ & $16(76)$ \\
Number of fetuses per litter & $11.1 \pm 1.6$ & $8.4 \pm 4.4$ \\
Number of viable fetuses per litter (\% of total) & $10.9 \pm 1.7(98)$ & $8.2 \pm 4.2(98)$ \\
Number of resorbing fetuses per litter (\% of total) & $0.2 \pm 0.4(2)$ & $0.2 \pm 0.4(2)$ \\
Number of implants examined at day 17 & 98 & 82 \\
Fetal weight (g) & $545 \pm 61$ & $555 \pm 76$ \\
Placental weight $(\mathrm{g})$ & $104 \pm 19$ & $105 \pm 14$ \\
Fetal weight:placental weight ratio & $5.3 \pm 0.9$ & $5.4 \pm 0.9$ \\
\hline
\end{tabular}

C57Bl/ 6 IL-5 + / + and IL-5 -/- mice were mated with Balb/c males of the same IL-5 genotype within $24 \mathrm{~h}$ of parturition, then killed at day 17 of pregnancy, when the numbers of viable and resorbing fetuses, as well as the fetal and placental weights and fetal:placental weight ratio were determined.

Data are given as mean $\pm \mathrm{SD}$.

Expression of the eosinophil-specific chemokine eotaxin is thought to be independent of IL-5, although IL-5 has been shown to be synergistic with eotaxin in promoting eosinophil migration (Mould et al., 1997). Eosinophil chemotactic factor (ECF-U), a molecule which may be related to or distinct from characterized eosinophil chemokines, is synthesized by endometrial stromal cells in rats and mice and has also been shown to be independent of the activity of IL-5 (Perez et al., 1996). These data are consistent with previous experiments showing that injection of oestrogen into immature IL-5-deficient female mice can elicit recruitment of eosinophils into the uterus, in a response with comparable kinetics but decreased amplitude relative to cytokine-replete animals (Kopf et al., 1996; K. Matthaei, unpublished). Taken together, these findings indicate that the eosinophils infiltrating the uterus at oestrus are drawn from the blood-borne pool under the influence of IL-5 independent chemokines, although some additional role as a chemokine cofactor cannot be ruled out. In contrast with allergic inflammatory episodes (Mould et al., 1997), uterine sequestration of eosinophils from the blood at oestrus most likely does not depend on mobilization of an IL-5 driven bone marrow pool.

The current data confirm and extend an existing study (Perez et al., 1996), in which the architecture and oestrogenresponsiveness of uterine tissues, as measured by the expression of oestrogen-regulated proteins including complement C3, were shown to be unaffected when eosinophil depletion was achieved by treatment in vivo with anti-IL-5 specific antibody. In addition, the present study shows that the duration of oestrus is extended moderately in IL-5deficient mice, as was demonstrated by the tracking of oestrous cycles and in 'mating interval' data showing more frequent receptivity to mating in cytokine-deficient mice. Eosinophils are rarely found in ovarian tissue (Brännström et al., 1993), so direct effects in the follicle or corpus luteum seem unlikely. An effect of IL-5 deficiency on cycle kinetics might be elicited indirectly through the influence of eosinophils on uterine determinants of follicular maturation, ovulation or luteal function. This notion is consistent with a role for these cells in transducing or modulating oestrogeninduced trophic changes in uterine tissues, a notion based 
originally on the observation of close temporal relationship between oestrogen-mediated uterine growth and the ontogeny and kinetics of uterine eosinophilia (Lee et al., 1989). Such a function could be mediated through eosinophil secretion of epithelial and fibroblast growth factors such as transforming growth factor $\alpha$ (TGF $\alpha$ ) and TGF $\beta$ (Yokota et al., 1987; Wong et al., 1990). While the current study shows that gross structural changes occur in the endometrium despite eosinophil depletion, it is reasonable to speculate that diminished eosinophil populations might be associated with a delay in achieving peak uterine responses to oestrogen. Alternatively, delayed responses to oestrogen withdrawal, perhaps including the synthesis of any luteolytic factors, might ensue if eosinophils are involved in endometrial tissue breakdown through their degranulation and release of cytotoxic proteins and superoxide molecules, or in the sequestration and inactivation of oestrogen (Klebanoff, 1965). Observations linking eosinophils with menstruation in the human endometrium support this latter alternative (Zhang et al., 2000). However, any role for eosinophils in uterine homeostasis must be of limited physiological significance since the present study showed that their depletion does not compromise the functional capacity of the endometrium to support embryo implantation and development.

Tissues taken from cyclic and early pregnant mice comprised the focus of the histological experiment in this study since uterine eosinophils are most prominent and exhibit their most dynamic fluctuations at this time. Eosinophils are rarely seen in the pregnant uterus and were not found in this or previous studies (Brandon, 1994) to be among the leukocytes that infiltrate the involuting nodules at the placental implantation site after parturition. In the current study, eosinophils were seen in the cervix of normal mice indicating that, in mice as in rats, eosinophils recruited into the cervical stroma at parturition have a role in cervical ripening or the recovery of this tissue after the birth process (Duchesne and Badia, 1992). However, the timing and success of parturition was unchanged in IL-5-deficient animals despite considerably decreased numbers of cervical eosinophils, indicating that any role is not obligatory. Moreover, recovery of the female reproductive tract after delivery did not appear to be delayed in IL-5-deficient mice, since new pregnancies initiated during the postpartum oestrus were sustained equally well regardless of IL-5 genotype.

The decreased placental efficiency and the subsequent increase in pup growth trajectory in IL-5-deficient pups is a significant finding in view of accumulating evidence from epidemiological and animal studies showing the importance of placental size as a determinant of fetal metabolic programming and weight gain in later life (Barker and Clark, 1997). The present observations are reminiscent of the accelerated placental and disproportionate fetal and postnatal growth observed in rats malnourished during midto-late gestation (Langley-Evans et al., 1996). Taken together, these considerations raise the possibility that IL- 5 has a role in establishing optimal placental function and consequently in defining metabolic 'set-points' in the fetus.

Interleukin 5 has been reported to be present in abundance in the decidual and placental tissues of mice (Lin et al., 1993), although its cellular origin has not been well characterized.
In women, synthesis occurs in uterine natural killer cells (Saito et al., 1993) and in type 2 polarized T lymphocytes, particularly after exposure to progesterone (Piccinni et al., 1995). The interaction between mating combination and IL-5 deficiency indicates that the role of IL-5 depends on the antigenic relationship between the mother and the conceptus, and may involve the maternal immune compartment. An immuno-regulatory role for the abundant eosinophil populations present in the uterus during early pregnancy may be important in view of evidence that the maternal immune response to paternal alloantigens are initiated at this time (Tafuri et al., 1995; Robertson et al., 1997). Through their antigen-presenting activity and cytokine synthesis respectively, eosinophils can influence both the activation and effector function of lymphocytes. Eosinophils have potent phagocytic and antigen processing capabilities, can express class II major histocompatibility complex antigens and stimulate T-lymphocyte activation in vitro (Weller and Lim, 1997). Through their secretion of cytokines, including IL-10 and TGF $\beta$ (Kroegel et al., 1994a; Nakajima et al., 1996), the presence of eosinophils in tissues appears to favour induction of type 2 immune responses (Wyss Coray et al., 1993). Alternatively, IL-5 deficiency may cause aberrations in other aspects of the immune response to pregnancy. IL-5 gene disruption would be expected to interfere with uterine humoral immune responses since, in other tissues, B lymphocyte proliferation and immunoglobulin synthesis are decreased to different extents depending on the tissue and antigen studied (Kopf et al., 1996, Whittle et al., 1997). IgA synthesis in B lymphocytes of the B1 $\left(\mathrm{CD}^{+}\right)$lineage are particularly dependent on IL-5 (Bao et al., 1998), and IgG $_{1}$ synthesis can also be substantially reduced in IL-5-deficient mice (Zhang and Denkers, 1999).

In summary, these experiments show that reproductive events proceed relatively unimpeded in the absence of IL- 5 and despite severe depletion of uterine eosinophils. The cost of accommodating IL-5 deficiency appears to be moderately less efficient placental function, and subsequent elicitation of a 'thrifty' phenotype in the newborn, to an extent that depends on the genotype of the fetus. These findings add to mounting evidence implicating a modulatory role for the maternal immune axis in placental development and hence fetal growth and viability. The precise nature of the eliciting mechanisms and physiological consequences of perturbation in utero in IL5-deficient mice, and the significance of the IL-5-eosinophilic axis in human reproduction, remain to be investigated.

The technical assistance of Aishling O'Connell is gratefully acknowledged. Our thanks also go to Wayne Damcevski and Helen Taylor for invaluable support in the Gene Targeting Transgenic Mouse Facility, and to David Armstrong for critical comments on the manuscript. This study was supported by NH\&MRC (Australia) project grants and an NH\&MRC R. Douglas Wright Award (S.A.R).

\section{References}

Austyn JM and Gordon S (1981) F4/80, a monoclonal antibody directed specifically against the mouse macrophage European Journal of Immunology 11 805-815

Bancroft JD and Stevens A (1990) Theory and Practice of Histological Techniques 3rd Edn. Churchill Livingstone, Edinburgh 
Bao S, Beagley KW, Murray AM, Caristo V, Matthaei KI, Young IG and Husband AJ (1998) Intestinal IgA plasma cells of the B1 lineage are IL-5 dependent Immunology 94 181-188

Barker DJ and Clark PM (1997) Fetal undernutrition and disease in later life Reviews of Reproduction 2 105-112

Brandon JM (1994) Distribution of macrophages in the mouse uterus from one day to three months after parturition, as defined by the immunohistochemical localization of the macrophage-restricted antigens F4/80 and macrosialin Anatomical Record 240 233-242

Brännström M, Mayrhofer G and Robertson SA (1993) Localisation of leukocyte subsets in the rat ovary during the periovulatory period Biology of Reproduction 248 277-286

Campbell HD, Sanderson CJ, Wang Y, Hort Y, Martinson ME, Tucker WQ, Stellwagen A, Strath M and Young IG (1988) Isolation, structure and expression of cDNA and genomic clones for murine eosinophil differentiation factor. Comparison with other eosinophilopoietic lymphokines and identity with interleukin 5 European Journal of Biochemistry 174 345-352

De M, Choudhuri R and Wood GW (1991) Determination of the number and distribution of macrophages, lymphocytes, and granulocytes in the mouse uterus from mating through implantation Journal of Leukocyte Biology $\mathbf{5 0}$ 252-262

Duchesne MJ and Badia E (1992) Immunohistochemical localization of the eosinophil major basic protein in the uterus horn and cervix of the rat at term and after parturition Cell and Tissue Research 270 79-86

Foster PS, Hogan SP, Ramsay AJ, Matthaei KI and Young IG (1996) Interleukin 5 deficiency abolishes eosinophilia, airways hyperreactivity, and lung damage in a mouse asthma model Journal of Experimental Medicine 183 195-201

Kinashi T, Harada N, Severinson E, Tanabe T, Sideras P, Konishi M, Azuma C, Tominaga A, Bergstedt-Lindqvist S, Takahashi M, et al. (1986) Cloning of complementary DNA encoding T-cell replacing factor and identity with B-cell growth factor II Nature 324 70-73

King WJ, Allen TC and DeSombre ER (1981) Localization of uterine peroxidase activity in estrogen-treated rats Biology of Reproduction 25 859-870

Klebanoff SJ (1965) Inactivation of estrogen by rat uterine preparations Endocrinology 76 301-307

Knudsen UB, Uldbjerg N, Rechberger T and Fredens K (1997) Eosinophils in human cervical ripening European Journal of Obstetrics and Gynaecology and Reproductive Biology 72 165-168

Kopf M, Brombacher F, Hodgkin PD, Ramsay AJ, Milbourne EA, Dai WJ, Ovington KS, Behm CA, Kohler G, Young IG and Matthaei KI (1996) IL-5deficient mice have a developmental defect in $\mathrm{CD}^{+}$B-1 cells and lack eosinophilia but have normal antibody and cytotoxic T-cell responses Immunity 4 15-24

Kroegel C, Virchow JC, Jr, Luttmann W, Walker C and Warner JA (1994a) Pulmonary immune cells in health and disease: the eosinophil leucocyte (Part I) European Respiratory Journal 7 519-543

Kroegel C, Warner JA, Virchow JC, Jr and Matthys H (1994b) Pulmonary immune cells in health and disease: the eosinophil leucocyte (Part II) European Respiratory Journal 7 743-760

Langley-Evans SC, Gardner DS and Jackson AA (1996) Association of disproportionate growth of fetal rats in late gestation with raised systolic blood pressure in later life Journal of Reproduction and Fertility 106 307-312

Lee YH, Howe RS, Sha SJ, Teuscher C, Sheehan DM and Lyttle CR (1989) Estrogen regulation of an eosinophil chemotactic factor in the immature rat uterus Endocrinology 125 3022-3028

Lin H, Mosmann TR, Guilbert L, Tuntipopipat S and Wegmann TG (1993) Synthesis of T-helper 2-type cytokines at the maternal-fetal interface Journal of Immunology 151 4562-4573

McMaster MT, Newton RC, Dey SK and Andrews GK (1992) Activation and distribution of inflammatory cells in the mouse uterus during the preimplantation period Journal of Immunology 148 1699-1705

Matthaei KI, Foster PS and Young IG (1997) The role of IL-5 in vivo: studies with IL-5-deficient mice. In New Perspectives in Eosinophils: Role in Inflammation Associated with Allergy, Asthma and Parasitic Disease Eds R Cordeiro, R Moqbel and PF Weller Memorias Instituto Oswaldo Cruz 92 63-68

Miyajima A, Mui AL, Ogorochi T and Sakamaki K (1993) Receptors for granulocyte-macrophage colony-stimulating factor, interleukin 3, and interleukin 5 Blood 82 1960-1974

Mould AW, Matthaei KI, Young IG and Foster PS (1997) Relationship between interleukin 5 and eotaxin in regulating blood and tissue eosinophilia in mice Journal of Clinical Investigation 99 1064-1071

Nakajima H, Gleich GJ and Kita H (1996) Constitutive production of IL-4 and IL-10 and stimulated production of IL-8 by normal peripheral blood eosinophils Journal of Immunology 156 4859-4866

Ovington KS, McKie KE, Matthaei KI, Young IG and Behm CA (1998) Regulation of primary Strongyloides ratti infections in mice: a role for interleukin 5 Immunology 95 488-493

Perez MC, Furth EE, Matzumura PD and Lyttle CR (1996) Role of eosinophils in uterine responses to estrogen Biology of Reproduction 54 249-254

Piccinni MP, Giudizi G, Biagiotti R et al. (1995) Progesterone favors the development of human $\mathrm{T}$ helper cells producing Th2-type cytokines and promotes both IL-4 production and membrane CD30 expression in established Th1 cell clones Journal of Immunology 155 128-133

Robertson SA, Mayrhofer G and Seamark RF (1992) Uterine epithelial cells synthesize granulocyte-macrophage colony-stimulating factor and interleukin 6 in pregnant and nonpregnant mice Biology of Reproduction 46 1069-1079

Robertson SA, Mau VJ, Tremellen KP and Seamark RF (1996) Role of high molecular weight seminal vesicle proteins in eliciting the uterine inflammatory response to semen in mice Journal of Reproduction and Fertility $107265-277$

Robertson SA, Mau VJ, Hudson SA and Tremellen KP (1997) Cytokine-leukocyte networks and the establishment of pregnancy American Journal of Reproductive Immunology 37 438-442

Robertson SA, Allanson M and Mau VJ (1998) Molecular regulation of uterine leukocyte recruitment during early pregnancy in the mouse Trophoblast Research 11 101-120

Ross R and Klebanoff SJ (1966) The eosinophilic leukocyte: fine structure studies of changes in the uterus during the estrous cycle Journal of Experimental Medicine 124 653-660

Saito S, Nishikawa K, Morii T, Enomoto M, Narita N, Motoyoshi K and Ichijo M (1993) Cytokine production by CD16-CD56bright natural killer cells in the human early pregnancy decidua International Immunology $\mathbf{5}$ 559-563

Sanderson CJ (1992) Interleukin 5, eosinophils, and disease Blood 79 3101-3109 Sanderson CJ, Campbell HD and Young IA (1988) Molecular and cellular biology of eosinophil differentiation factor (interleukin 5) and its effects on human and mouse B cells Immunological Reviews 102 29-50

Tafuri A, Alferink J, Moller P, Hammerling GJ, Arnold B (1995) T-cell awareness of paternal alloantigens during pregnancy Science 270 630-633

Takamoto M, Ovington KS, Behm CA, Sugane K, Young IG and Matthaei KI (1997) Eosinophilia, parasite burden and lung damage in Toxocara canis infections in C57BL/6 mice genetically deficient in IL-5 Immunology 90 511-517

Weller PF and Lim K (1997) Human eosinophil-lymphocyte interactions. In New Perspectives in Eosinophils: Role in Inflammation Associated with Allergy, Asthma and Parasitic Disease Eds R Cordeiro, R Moqbel and PF Weller Memorias Instituto Oswaldo Cruz 92 173-182

Whittle BL, Smith RM, Matthaei KI, Young IG and Verma NK (1997) Enhancement of the specific mucosal $\mathrm{IgA}$ response in vivo by interleukin 5 expressed by an attenuated strain of Salmonella serotype Dublin Journal of Medical Microbiology 46 1029-1038

Wong DT, Weller PF, Galli SJ et al. (1990) Human eosinophils express transforming growth factor alpha Journal of Experimental Medicine $\mathbf{1 7 2}$ 673-681

Wyss-Coray T, Gallati H, Pracht I, Limat A, Mauri D, Frutig K and Pichler WJ (1993) Antigen-presenting human T cells and antigen-presenting B cells induce a similar cytokine profile in specific T cell clones European Journal of Immunology 23 3350-3357

Yokota T, Coffman RL, Hagiwara H et al. (1987) Isolation and characterization of lymphokine cDNA clones encoding mouse and human IgA-enhancing factor and eosinophil colony-stimulating factor activities: relationship to interleukin 5 Proceedings National Academy of Sciences USA 84 7388-7392

Zhang J, Lathbury LJ and Salamonsen LA (2000) Expression of the chemokine eotaxin and its receptor, CCR3, in human endometrium Biology of Reproduction 62 404-411

Zhang Y and Denkers EY (1999) Protective role for interleukin-5 during chronic Toxoplasma gondii infection Infection and Immunity 67 4383-4392 